\title{
Computational Approaches for the Discovery of GPER Targeting Compounds
}

\section{OPEN ACCESS}

Edited by:

Michael A. Weiss,

Indiana University, United States

Reviewed by:

Tony Ngo,

University of California, San Diego,

United States

Martiniano Bello Ramirez,

Superior de Medicina del Instituto

Politécnico Nacional, Mexico

*Correspondence:

Fedora Grande

fedora.grande@unical.it

Bruno Rizzuti

bruno.rizzuti@cnr.it

Specialty section

This article was submitted to Molecular and Structural

Endocrinology,

a section of the journal

Frontiers in Endocrinology

Received: 23 April 2020

Accepted: 26 June 2020

Published: 04 August 2020

Citation:

Grande F, Occhiuzzi MA, Lappano R,

Cirillo $F$, Guzzi $R$, Garofalo $A$,

Jacquot $Y$, Maggiolini $M$ and Rizzuti $B$ (2020) Computational Approaches for

the Discovery of GPER Targeting

Compounds.

Front. Endocrinol. 11:517. doi: 10.3389/fendo.2020.00517

\begin{abstract}
Fedora Grande ${ }^{1 *}$, Maria A. Occhiuzzi ${ }^{1}$, Rosamaria Lappano ${ }^{1}$, Francesca Cirillo ${ }^{1,2}$, Rita Guzzi ${ }^{2,3}$, Antonio Garofalo ${ }^{1}$, Yves Jacquot ${ }^{4}$, Marcello Maggiolini ${ }^{1}$ and Bruno Rizzuti ${ }^{3 *}$

${ }^{1}$ Department of Pharmacy, Health and Nutritional Sciences, University of Calabria, Rende, Italy, ${ }^{2}$ Department of Physics, University of Calabria, Rende, Italy, ${ }^{3}$ CNR-NANOTEC, Licryl-UOS Cosenza and CEMIF.Cal, Department of Physics, University of Calabria, Rende, Italy, ${ }^{4}$ Cibles Thérapeutiques et Conception de Médicaments (CiTCOM), CNRS UMR 8038, INSERM U1268, Faculté de Pharmacie de Paris, Université de Paris, Paris, France
\end{abstract}

Estrogens exert a panel of biological activities mainly through the estrogen receptors $\alpha$ and $\beta$, which belong to the nuclear receptor superfamily. Diverse studies have shown that the G protein-coupled estrogen receptor 1 (GPER, previously known as GPR30) also mediates the multifaceted effects of estrogens in numerous pathophysiological events, including neurodegenerative, immune, metabolic, and cardiovascular disorders and the progression of different types of cancer. In particular, GPER is implicated in hormone-sensitive tumors, albeit diverse issues remain to be deeply investigated. As such, this receptor may represent an appealing target for therapeutics in different diseases. The yet unavailable complete GPER crystallographic structure, and its relatively low sequence similarity with the other members of the $G$ protein-coupled receptor (GPCR) family, hamper the possibility to discover compounds able to modulate GPER activity. Consequently, a reliable molecular model of this receptor is required for the design of suitable ligands. To date, convergent approaches involving structure-based drug design and virtual ligand screening have led to the identification of several GPER selective ligands, thus providing important information regarding its mode of action and function. In this survey, we summarize results obtained through computer-aided techniques devoted to the assessment of GPER ligands toward their usefulness in innovative treatments of different diseases.

Keywords: G protein-coupled estrogen receptor 1, estrogen receptors, ligands, drug design, molecular docking, molecular dynamics

\section{INTRODUCTION}

The multifaceted responses to estrogens are principally mediated by the estrogen receptors (ERs) $\alpha$ and $\beta$, which act as transcription factors by binding to estrogen response elements (EREs) located in the promoter regions of target genes (1). Recently, a seven-transmembrane $\mathrm{G}$ protein-coupled receptor, known as G protein estrogen receptor (GPER), has attracted the attention of several researcher groups working on the identification of the intricate estrogen routes in different biological systems. A panel of experiences has highlighted the involvement of GPER in various pathophysiological processes. For instance, its role in hormone-dependent cancers has been addressed in several studies, providing a better understanding of the related gene landscape 
and transduction pathways. In particular, GPER modulates signaling processes leading to the transcription of genes promoting tumor growth in vitro and in vivo, such as calcium mobilization, cAMP synthesis, the cleavage of matrix metalloproteinases, the transactivation of epidermal growth factor receptor (EGFR) and the activation of PI3K and MAPK transduction pathways (2-11). To date, GPER expression has been correlated with negative cancer features including increased tumor size, distant metastasis and tumor recurrence (12-14). In addition, a bioinformatic analysis of large cohorts of patients has recently demonstrated that GPER expression is correlated with the expression of pro-metastatic genes in ER-negative breast tumors (15). On the basis of the aforementioned findings, this receptor might be considered as a promising therapeutic target for the treatment of diverse types of tumors, including breast cancer. Nevertheless, other studies reached different conclusions (16), therefore indicating that further investigations are required to better appreciate the role exerted by GPER in cancer.

Most estrogens and anti-estrogens are able to bind to GPER and ERs, albeit with a different affinity and even with an opposite action (i.e., agonism vs. antagonism) (10, 17, 18). Considering the interest to identify specific GPER ligands to decipher its unique potential, several successful efforts have been made during the last few years (19-25). In this context, it should be mentioned the intriguing discovery of the indole derivative MIBE, which has the property of binding to and antagonizing the effects of both GPER and ER, thus representing a useful tool toward more comprehensive approaches in estrogen-dependent tumors (22).

The overall structural heterogeneity among agents targeting these receptors constitutes an obstacle to identify agonists or antagonists and to predict their effects. Thus, the design of potent selective GPER ligands and dual ER/GPER inhibitors is still challenging. While the crystallographic structure of the ER ligand-binding domain is available, the detailed structure of GPER remains yet unsolved due to the well-known difficulties in fully characterizing membrane proteins. Nevertheless, a homology model of GPER can be obtained with the help of computational techniques (Figure 1), allowing access to relevant structural information. More importantly, virtual ligand screening approaches and structure-based drug design methods can support experiments aiming to identify new GPER ligands. The results obtained by application of computational techniques are herein summarized toward their adoption as starting point for the design and development of novel active agents.

\section{THE EARLY AGE OF LIGAND-BASED DESIGN FOR TARGETING GPER}

With respect to the computational design of GPER ligands, one of the earliest achievements is indisputably the synthesis of the quinoline G-1 (19). To this aim, a library of 10,000 candidate molecules has been analyzed by combining their

Abbreviations: AhR, aryl hydrocarbon receptor; E2, 17 $\beta$-estradiol; E3, 16 $\alpha, 17 \beta$ estriol; EGFR, epidermal growth factor receptor; ER, estrogen receptor; ERE, estrogen response element; GPCR, G protein-coupled receptor; GPER (or GPR30), $\mathrm{G}$ protein-coupled estrogen receptor 1; MD, molecular dynamics.

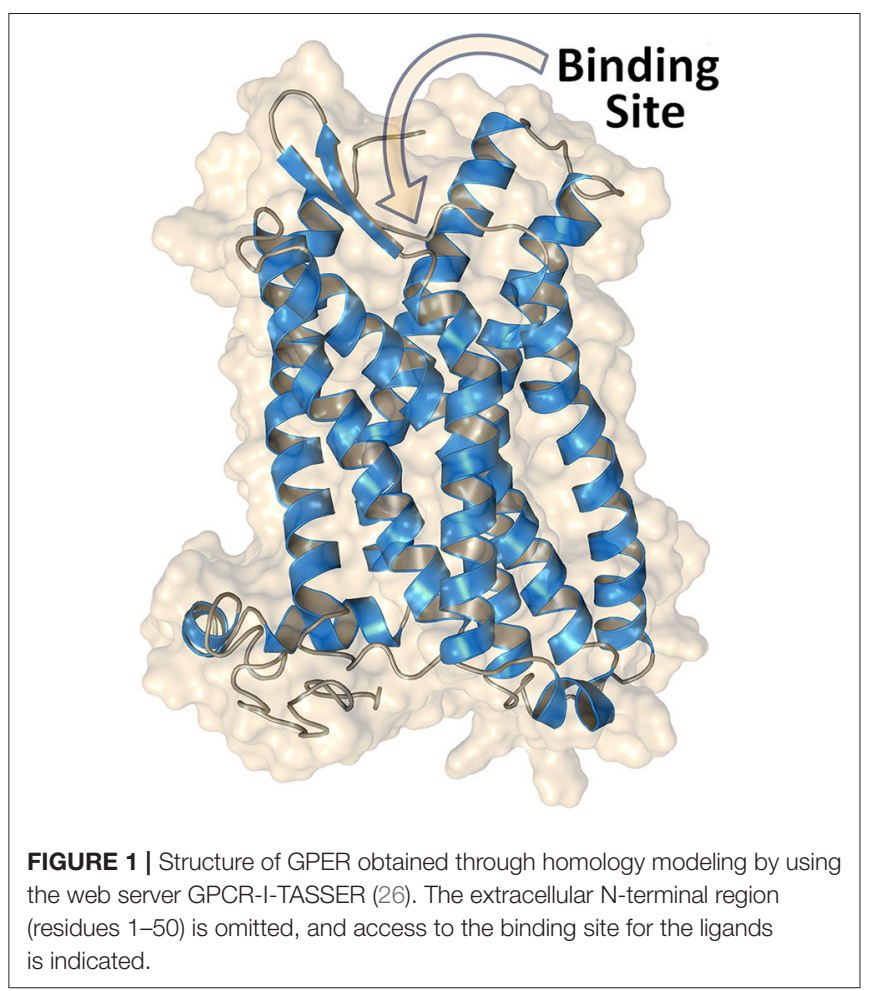

structural features in common with the archetypal ligand $17 \beta$-estradiol (E2). Three distinct categories of criteria were defined: (i) 2D structural patterns, including both symmetric and asymmetric features, (ii) $3 \mathrm{D}$ shape analogies and metrics and (iii) pharmacophore-based motifs, including hydrogen-bond donors/acceptors and the possibility of forming hydrophobic interactions. The resulting computational analysis was completed with an in vitro biomolecular screening to validate the occurrence of a competitive ligand binding. The molecule G-1 (for the chemical structure of this compound and all the other mentioned throughout the text, see Figure 2) has emerged from this screening funnel as the first GPER-specific agonist able to activate the receptor in cells expressing both GPER and ERs. A similar virtual screening methodology, applied on a larger library with more than 140,000 compounds, led successively to the identification of a high-affinity GPER ligand named G-15, a G-1 analog acting as a selective antagonist (20).

The success of these original ligand-based virtual screenings was facilitated by the limited number of internal degrees of freedom of the studied compounds. These observations referred also to the conformational space of the ligand-binding pocket of the different steroid hormone receptors (27). In the absence of a model for the GPER tertiary structure, the previous works were, therefore, expanded to an "indirect" structure-based approach consisting in the analysis into deeper details of the ER $\alpha$ and $\operatorname{ER} \beta$ binding sites. In fact, the main concern was to focus on the acetyl moiety of the ER agonist G-1, which is lacking in the antagonist G-15 (21). Molecular docking was then performed to explore the possibility to increase steric clashes within the binding pocket of the ERs through an isopropyl moiety instead of 
<smiles>CC(C)[C@H]1CCC2C(CCC3C(O)CCC32)c2ccc(O)cc21</smiles>

(17ß-Estradiol)<smiles>[R]c1ccc2c(c1)C1C=CCC1C(c1cc3c(cc1O)OCO3)N2</smiles><smiles>CC1(O)CCC2C(C1)C1C2c2ccc(O)cc2C[C@@H]1CCCCCCCCCCS(=O)CCCC(F)(F)C(F)(F)F</smiles><smiles>[R]c1ccc(C(=C(CC)c2ccccc2)c2ccc(OCCN(C)C)cc2)cc1</smiles>

Tamoxifen $(\mathrm{R}=\mathrm{H})$ 4-Hydroxytamoxifen $(\mathrm{R}=\mathrm{OH})$<smiles>S=C1NCCN1C(Sc1ccccc1)Sc1ccccc1</smiles>

GPER-L2
G-1 $(R=$ COMe $)$ $G-15(R=H)$ $\mathrm{G}-36\left(\mathrm{R}=\mathrm{CHMe}_{2}\right)$<smiles>CCOC(=O)/C=C(/C)c1cn(C)c2ccc(O/C(C)=C/OC(=O)CC)cc12</smiles>

MIBE<smiles>CC1(O)C(O)CC2C3CCc4cc(O)ccc4C3CCC21</smiles>

E3

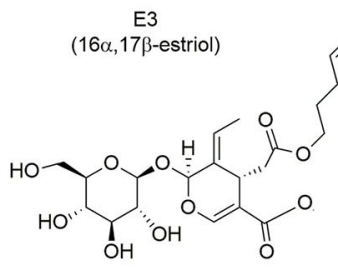

Oleuropein<smiles>CCN(CC)CCNc1nc2c(c(=S)n1-c1ccccc1)c(=N)n(-c1ccccc1)c(=S)n2-c1ccccc1</smiles>

GPER-L1<smiles>OCCc1ccc(O)c(O)c1</smiles>

Hydroxytyrosol<smiles>O=c1oc2cc(Nc3cnc4ccccc4n3)ccc2n2cccc12</smiles>

PBX-1<smiles>COc1cc(C(=O)Nc2ccc3c(c2)oc(=O)c2cccn23)cc(OC)c1OC</smiles>

PBX-2<smiles>[R]c1ccc2[nH]c3c(C)cc(/C=N/N)c(C)c3c2c1</smiles>

Carbhydraz 2a $(\mathrm{R}=\mathrm{Br})$ Carbhydraz 2b ( $R=\mathrm{OMe})$<smiles>[R]C(=O)c1cccnc1</smiles>

Niacin $(\mathrm{R}=\mathrm{OH})$

Niacinamide $\left(\mathrm{R}=\mathrm{NH}_{2}\right)$<smiles>Oc1cc(O)c2c(c1)O[C@H](c1ccc(O)c(O)c1)[C@H](O)C2</smiles>

(-)-Epicatechin $(\mathrm{R}=\mathrm{H})$ Epi-Ms $\left(\mathrm{R}=\mathrm{SO}_{2} \mathrm{Me}\right)$<smiles>Oc1cc(O)c2c(c1)O[C@H](c1ccc(O)c(O)c1)[C@H](O)C2</smiles>

Epi-4-prop ( $R=$ propargyl, $R^{\prime}=H$ ) Epi-5-prop $\left(R=R^{\prime}=\right.$ propargyl) Epi-prop $\left(R=H, R^{\prime}=\right.$ propargyl)<smiles>O=C([O-])c1ccc2c(c1)C1C=CCC1C(c1cc3c(cc1Br)OCO3)N2</smiles><smiles>[R]c1ccc(C2Nc3ccc(C(=O)N4CCC[C@H]4C(=O)OC)cc3C3CC=CC32)cc1Br</smiles>

G1-PABA $(R=H)$ G1-PABA methylester $(R=M e)$

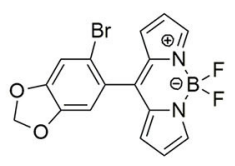

Bodipy 1<smiles>COc1cc(CC(COC2OC(CO)[C@@H](O)[C@H](O)C2O)C(COC2OC(CO)[C@@H](O)[C@H](O)[C@H]2O)Cc2ccc(O)c(OC)c2)ccc1O</smiles>

Secoisolariciresinol diglucoside<smiles>O=C1OCC(Cc2cccc(O)c2)[C@H]1Cc1cccc(O)c1</smiles>

Enterolactone<smiles>O=c1cc(-c2ccccc2)oc2cc(O)c(O)c(O)c12</smiles>

Baicalein<smiles>[R]C([R])(c1ccc(O)cc1)c1ccc(O)cc1</smiles>

Bisphenol $\mathrm{AF}\left(\mathrm{R}=\mathrm{R}^{\prime}=\mathrm{CF}_{3}\right)$ Bisphenol $B\left(R=M e, R^{\prime}=E t\right)$

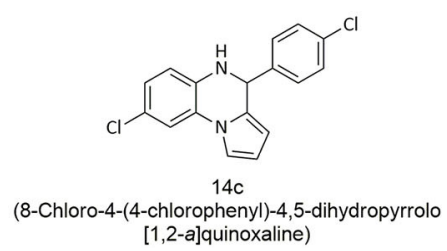<smiles></smiles>

3-Methylcholanthrene

FIGURE 2 | GPER ligands investigated by computational methods. Typical ligands (represented in red), including E2, fulvestrant, and tamoxifen, have been extensively tested in simulation as reference GPER binders. All the other ligands (in black) were discovered or characterized through virtual screening techniques. 
the acetyl group. The resulting compound, named G-36, showed an enhanced selectivity with an antagonist effect toward GPER, and a low-affinity cross-reactivity toward ER $\alpha$.

\section{HOMOLOGY MODELING FOR PREDICTING THE STRUCTURE OF GPER}

The possibility of investigating in simple and accurate ways the binding location and the affinity of molecules to GPER is intimately linked with the availability of a correct molecular description of the protein structure. The first crude GPER model was built to predict ligand binding, through computational approaches (28). A more accurate structure of GPER was later used as a support to elucidate a number of "wet-lab" experiments $(18,22,29)$. In all cases, a special emphasis was put on providing details about the topology of the putative binding-site of the protein, rather than the whole protein tertiary structure. The 3D structure of GPER was constructed through homology modeling $(30,31)$, by using the crystal structure of bovine rhodopsin (32) as a template.

Subsequent efforts were devoted on the improvement of the molecular description of the protein structure, with a broader emphasis on the description of the overall protein architecture. Consistent results were achieved by using as a template the $\mathrm{X}$ ray structure of the $\beta_{2}$-adrenergic receptor, which was found to possess a higher degree of homology with GPER, when compared to bovine rhodopsin. The crystal structures of both the active and inactive states of the $\beta_{2}$-adrenergic receptor were available $(33,34)$, allowing to model different conformations of GPER in complex with agonists or antagonists (35).

Alternatively, GPER has been modeled (36) by using as a template the crystallographic structure of the chemokine receptor CXCR4 (37). It was also possible to identify some structural differences between agonists and antagonists, depending on their ability to form hydrogen bonds with key residues located in specific transmembrane helices. The quality level of this new GPER model was further improved through molecular dynamics (MD) simulations $(36,38,39)$, which were helpful to take into account the internal dynamics of the protein, concomitantly to the contribution of the surrounding lipid matrix.

A more comprehensive view of the $3 \mathrm{D}$ structure of GPER has been recently obtained by using the web server GPCR-ITASSER $(26,40)$, which is a computational suite derived from the parent I-TASSER package (41), one of the most popular online resources for protein structure prediction and refinement. A major strength of the algorithm used in GPCR-I-TASSER is that it was specifically devised for the prediction of GPCRs and, as such, it works with a dedicated knowledge-based force field as a guide for an accurate assembly of the receptor structure. A number of works $(25,38,42,43)$ have adopted this computational tool to design high-quality GPER models (see again Figure 1). Highquality and tailored software, together with the growing number of experimentally-determined GPCR structures that can be used as GPER templates, are contributing to make homology modeling algorithms more accurate in predicting the receptor structure.

\section{THE BEGINNING OF STRUCTURE-BASED DESIGN OF LIGANDS FOR GPER}

In the last decade, one of the major aims of our research group has been the identification of novel GPER ligands supported by computational drug discovery approaches. A first result (18) was the identification of $16 \alpha, 17 \beta$-estriol (E3) as a GPER antagonist (see Figure 2). This compound, which corresponds to a final metabolite of E2 (44), is one of the three natural estrogens produced by the human body (i.e., estradiol, estrone, and estriol). It is of note that E3 can also be biosynthesized from estrone sulfate as well as from testosterone and androstenedione (44).

A computational analysis also allowed the discovery of two new molecules (22), named GPER-L1 and GPER-L2, both acting on GPER as selective agonists but unable to bind and activate ERs. These two ligands were selected through a typical process of virtual screening starting from a chemical library including more than 300 molecules. Despite strong differences in their chemical structure, they share some crucial features such as the ability of exposing a phenyl ring into a hydrophobic protein pocket and, thereby, of forming stabilizing $\pi-\pi$ stacking interactions. Due to their selectivity, these molecules contribute to increase our understanding of the function of various cancer phenotypes, through different estrogen-targeted receptors.

In sharp contrast, MIBE was identified as a unique case of dual antagonist for both GPER and ER $\alpha$ (29), by using molecular docking. The possibility of targeting simultaneously GPER and $\mathrm{ER} \alpha$ is particularly interesting from a pharmacological point of view, because active compounds antagonizing both proteins could be useful in tackling breast carcinomas at the initial stage or during their progression. In a subsequent work (45), it was demonstrated that oleuropein and hydroxytyrosol, two natural phenols, were able to bind GPER. Flexible molecular docking calculations were performed with these two molecules, considering free rotation of seven bulky side chains in the binding site of the receptor, which was especially required to accommodate the relatively large molecular structure of oleuropein. The following experiments demonstrated that both ligands act as GPER inverse agonists in ER-negative and GPERpositive $\mathrm{SkBr} 3$ breast cancer cells, as recently found with the peptide $E R \alpha 17$ p (25).

A virtual screening campaign on a library of chemical fragments demonstrated the binding of niacin (also known as nicotinic acid, vitamin B3, or vitamin PP) and of its amide form niacinamide (or nicotinamide) to GPER and niacin receptor GPR109A/HCA2 (46). The latter is a subtype of the receptor GPR109 that mainly, although not exclusively, mediates the action of niacin (but not of niacinamide). Sequence alignment revealed a lack of homology between GPER and GPR109A, at least in their ligand-binding sites, thus the anchoring of these two molecules to both GPER and GPR109A was not obvious. Nevertheless, molecular docking suggested some similarities in the binding mode of the pyridine ring of both compounds. The presence of two important arginine residues able to form hydrogen bonds with the carboxylic acid moiety of niacin, allowing GPR109A specificity, were also highlighted. Both niacin 
and niacinamide were demonstrated to exert an agonist activity toward GPER in the successive experiments.

Computational techniques further helped to design two novel benzopyrroloxazines (24) acting as selective GPER antagonists. The starting point was the virtual screening of a compound library and the identification of a rigid molecular structure closely resembling the chemical skeleton of other known GPER ligands. This structure was used as a template and two derivatives, named PBX1 and PBX2, were demonstrated to bind to GPER. To this aim, flexible molecular docking was performed by allowing the rotation of the dihedral angles in the side chain of eight residues within the protein-binding site.

In a separate study (23), two novel carbazole derivatives were synthesized. While both of them did not activate the classical $\mathrm{ER} \alpha$, one of them, abbreviated as carbhydraz 2a, showed a favorable affinity for GPER, as shown by docking assays with seven flexible residues. This compound was then shown to display an agonistic response on GPER.

As a final example, a rational design has been completed with the first GPER selective fluorescent organoboron probe (47), which consists in a boron-dipyrromethene difluoride derivative. In this case, the starting molecular template was a bromobenzodioxolyl substituent, which is also present in the structure of G-1 and constitutes a key motif for GPER binding. Using molecular docking, the obtained compound, named Bodipy 1, was predicted to share a binding mode similar to G-1, by interacting with the key protein residue Phe-208 and by forming $\pi-\pi$ stacking with its bromobenzodioxole moiety. Bodipy 1 was later demonstrated to compete with niacin in ER-negative and GPER-positive $\mathrm{SkBr} 3$ breast cancer cells.

\section{THE CURRENT AREA OF COMPUTATIONAL METHODS FOR STUDYING GPER}

The study of GPER through theoretical modeling approaches has lately benefited from a number of improvements, including the use of targeted simulations to capture important aspects of the protein dynamics. Molecular docking on GPER structures extracted from all-atom MD has demonstrated (48) that the natural polyphenol (-)-epicatechin (see Figure 2) has the ability to anchor to this receptor with a binding mode similar to the agonist G-1. It is interesting to note that flavonoids sharing structural similarities to estrogens, such as genistein and other phytoestrogens (49-51), not only bind but also activate the classical receptors $\mathrm{ER} \alpha$ and $\mathrm{ER} \beta$. In contrast, and in spite of its evident structural analogies to these phytochemicals, (-)epicatechin fails to bind $\mathrm{ER} \alpha$ and $\mathrm{ER} \beta$. Since (-)-epicatechin can associate within the GPER binding pocket, an important role of this receptor on cardiovascular system protection seems likely. In a subsequent study (52), (-)-epicatechin derivatives were obtained where the phenol and alcohol groups are functionalized with a propargyl or a mesyl group. The resulting compounds, i.e., Epi-4-prop, Epi-5-prop, Epi-prop and Epi-Ms, were investigated by docking methods on the GPER structures obtained through MD. Strikingly, it was observed that the alkyne function of the propargyl was prone to generate additional interactions in the receptor-binding site and to enhance the GPER agonistic activity, when compared to the parent compound. Later, MD simulations showed that Epi-4-prop and Epi-5-prop share with (-)-epicatechin similar interactions at the GPER binding site (53).

A number of additional GPER binders have also been identified using theoretical modeling calculations. It is the case of G1-PABA (54), a compound part of a small series of G1 analogs, in which the acetyl moiety is replaced with a carboxyl group. The same pharmacophore core was further used to obtain a G1-PABA methylester and $L$-proline derivative, with similar structural and energetic binding properties (55). All these newly synthesized compounds were validated in vitro in experimental assays using breast cancer cell lines. Another example is secoisolariciresinol diglucoside, a phytoestrogen extracted from flaxseed and able to suppress benign prostatic hyperplasia (56), which was indirectly investigated through molecular docking of its mammalian metabolite enterolactone (57). Similarly, the binding mode to both GPER and ER $\alpha$ of baicalein, a flavonoid derived from the roots of a medicinal herb, has been extensively studied (58). Molecular docking analysis was especially focused on the hydrogen-bond network favoring the ligand binding. The observation that GPER appeared to mediate the estrogenic effects of some bisphenol A analogs was the starting point of another computational study (59), which predicted a favorable binding of bisphenol AF and bisphenol B. Experimental assays have confirmed the agonistic activity of these compounds, supporting the hypothesis of their disrupting action on the GPER-mediated pathway. These observations clearly highlight the lack of selectivity of phytoestrogens (60).

Similarly to G-15, theoretical methods have also been used to identify new compounds (61) with a selective anti-proliferative activity against GPER-expressing breast cancer cells. A virtual screening campaign was carried out on a chemical library of about 1,000 compounds, in search of molecules showing a binding mode close to G-15 and G-36. They were selected on the basis of their binding score and by visual inspection, as well as their ability to form polar contacts with previously identified GPER residues. Four different chemical scaffolds were found. A particularly promising compound, named $14 \mathrm{c}$ and based on one of these scaffolds, has been proposed as a starting point for a future hit-to-lead optimization process.

By using combined docking and MD simulations approach, the association of the chemical carcinogen 3-methylcholanthrene with GPER has been recently studied (43). This environmental pollutant, which is generated by incomplete combustion processes including cigarette smoke, was known to bind to both ER $\alpha$ and the aryl hydrocarbon receptor (AhR), stimulating thereby a functional interaction between these two receptors. The results pointed out to a functional crosstalk and a crossstimulation between GPER and AhR. Computational methods have also been used to investigate the binding to GPER of the peptide ER $\alpha 17 \mathrm{p}$, which encompasses a part of the hinge region/AF2 domain of the human $\mathrm{ER} \alpha(25,62)$. This peptide acts as a GPER inverse agonist and shows anti-proliferative effects in breast cancer cells and a decrease in the volume of breast 
tumors in xenografted mice (63). The N-terminal PLMI motif of this peptide presents some chemical analogies with the GPER antagonist PBX1 and exerts the same anti-proliferative potency as the whole length peptide $(25,62)$, suggesting strongly that this region corresponds to the active motif. Due to the large number of rotatable bonds in ER $\alpha 17 \mathrm{p}, \mathrm{MD}$ simulations were necessary to map the conformational landscape of the receptorpeptide molecular system. The fact that a specific amino acid drives the anchoring of $\mathrm{ER} \alpha 17 \mathrm{p}$ opens the way to the possibility of modulating GPER by using peptide-based compounds. It is particularly notable that ER $\alpha 17 \mathrm{p}$ is, to the best of our knowledge, the first peptidic GPER modulator.

\section{CONCLUSIONS}

GPER is increasingly recognized as a mediator of different estrogen-dependent pathophysiological responses, such as those that characterize cancer progression. The persistent difficulty in obtaining an experimental structure of the native structure of this membrane receptor, let alone in complex with any endogenous or exogenous ligands, has prompted an abundance of theoretical studies to clarify its conformation and binding properties. In this context, molecular modeling of GPER ligands has demonstrated that targeting this receptor with computational methods is feasible. Accordingly, a number of compounds has been defined toward the development of innovative molecular modulators of GPER action in different biological systems. In

\section{REFERENCES}

1. Geserick C, Meyer HA, Haendler B. The role of DNA response elements as allosteric modulators of steroid receptor function. Mol Cell Endocrinol. (2005) 236:1-7. doi: 10.1016/j.mce.2005.03.007

2. Barton M, Filardo EJ, Lolait SJ, Thomas P, Maggiolini M, Prossnitz ER. Twenty years of the G protein-coupled estrogen receptor GPER: historical and personal perspectives. J Steroid Biochem Mol Biol. (2018) 176:4-15. doi: 10.1016/j.jsbmb.2017.03.021

3. Pandey DP, Lappano R, Albanito L, Madeo A, Maggiolini M, Picard D. Estrogenic GPR30 signalling induces proliferation and migration of breast cancer cells through CTGF. EMBO J. (2009) 28:523-32. doi: 10.1038/emboj.2008.304

4. De Francesco EM, Pellegrino M, Santolla MF, Lappano R, Ricchio E, Abonante $\mathrm{S}$, et al. GPER mediates activation of HIF1 $\alpha /$ VEGF signaling by estrogens. Cancer Res. (2014) 74:4053-64. doi: 10.1158/0008-5472.CAN-13-3590

5. De Marco P, Lappano R, De Francesco EM, Cirillo F, Pupo M, Avino S, et al. GPER signalling in both cancer-associated fibroblasts and breast cancer cells mediates a feedforward IL1 $\beta /$ IL1R1 response. Sci Rep. (2016) 6:24354. doi: $10.1038 /$ srep 24354

6. Rigiracciolo DC, Santolla MF, Lappano R, Vivacqua A, Cirillo F, Galli GR, et al. Focal adhesion kinase (FAK) activation by estrogens involves GPER in triple-negative breast cancer cells. J Exp Clin Cancer Res. (2019) 38:58. doi: 10.1186/s13046-019-1056-8

7. Lappano R, Pisano A, Maggiolini M. GPER function in breast cancer: an overview. Front Endocrinol. (2014) 5:66. doi: 10.3389/fendo.2014.00066

8. Santolla MF, Vivacqua A, Lappano R, Rigiracciolo DC, Cirillo F, Galli GR, et al. GPER mediates a feedforward FGF2/FGFR1 paracrine activation coupling CAFs to cancer cells toward breast tumor progression. Cells. (2019) 8:223. doi: $10.3390 /$ cells 8030223

9. Cirillo F, Pellegrino M, Malivindi R, Rago V, Avino S, Muto L, et al. GPER is involved in the regulation of the estrogen-metabolizing particular, the first identified GPER agonist, G-1, is currently undergoing phase 1 clinical trials for its immunomodulatory and antineoplastic properties. In this respect, the findings recapitulated and discussed herein could be useful in order to clarify the potential role of GPER in cancer and other diseases, and the advantages of computational approaches to drive drug discovery for this target.

\section{AUTHOR CONTRIBUTIONS}

All the authors have contributed to prepare the manuscript and approved it for publication.

\section{FUNDING}

MM was supported by Fondazione AIRC (IG n. 21322).

\section{ACKNOWLEDGMENTS}

FG, MO, RL, AG, and MM acknowledge (i) the special award Department of Excellence 2018-2022 (Italian Law 232/2016) to the Department of Pharmacy, Health and Nutritional Sciences of the University of Calabria (Italy), (ii) the Sistema Integrato di Laboratori per L'Ambiente-(SILA) PONa3_00341. YJ acknowledges CNRS, INSERM and the University of Paris (Paris 5).
CYP1B1 enzyme in breast cancer. Oncotarget. (2017) 8:106608-24. doi: 10.18632/oncotarget.22541

10. Filardo EJ, Quinn JA, Bland KI, Frackelton AR Jr. Estrogen-induced activation of Erk-1 and Erk-2 requires the G protein-coupled receptor homolog, GPR30, and occurs via trans-activation of the epidermal growth factor receptor through release of HB-EGF. Mol Endocrinol. (2000) 14:1649-60. doi: $10.1210 /$ mend.14.10.0532

11. Marjon NA, Hu C, Hathaway HJ, Prossnitz ER. G protein-coupled estrogen receptor regulates mammary tumorigenesis and metastasis. Mol Cancer Res. (2014) 12:1644-54. doi: 10.1158/1541-7786.MCR-14-0128-T

12. Filardo EJ, Graeber CT, Quinn JA, Resnick MB, Giri D, DeLellis RA, et al. Distribution of GPR30, a seven membrane-spanning estrogen receptor, in primary breast cancer and its association with clinicopathologic determinants of tumor progression. Clin Cancer Res. (2006) 12:6359-66. doi: 10.1158/1078-0432.CCR-06-0860

13. Smith HO, Leslie KK, Singh M, Qualls CR, Revankar CM, Joste NE, et al. GPR30: a novel indicator of poor survival for endometrial carcinoma. Am J Obstet Gynecol. (2007) 196:386.e1. doi: 10.1016/j.ajog.2007.01.004

14. Smith HO, Arias-Pulido H, Kuo DY, Howard T, Qualls CR, Lee SJ, et al. GPR30 predicts poor survival for ovarian cancer. Gynecol Oncol. (2009) 114:465-71. doi: 10.1016/j.ygyno.2009.05.015

15. Talia M, De Francesco EM, Rigiracciolo DC, Muoio MG, Muglia L, Belfiore A, et al. The $\mathrm{G}$ protein-coupled estrogen receptor (GPER) expression correlates with pro-metastatic pathways in ER-negative breast cancer: a bioinformatics analysis. Cells. (2020) 9:622. doi: 10.3390/cells9030622

16. Martin SG, Lebot MN, Sukkarn B, Ball G, Green AR, Rakha EA, et al. Low expression of G protein-coupled oestrogen receptor 1 (GPER) is associated with adverse survival of breast cancer patients. Oncotarget. (2018) 9:25946-56. doi: 10.18632/oncotarget.25408

17. Thomas P, Pang Y, Filardo EJ, Dong J. Identity of an estrogen membrane receptor coupled to a $\mathrm{G}$ protein in human breast cancer cells. Endocrinology. (2005) 146:624-32. doi: 10.1210/en.2004-1064 
18. Lappano R, Rosano C, De Marco P, De Francesco EM, Pezzi V, Maggiolini M. Estriol acts as a GPR30 antagonist in estrogen receptor-negative breast cancer cells. Mol Cell Endocrinol. (2010) 320:162-70. doi: 10.1016/j.mce.2010.02.006

19. Bologa CG, Revankar CM, Young SM, Edwards BS, Arterburn JB, Kiselyov AS, et al. Virtual and biomolecular screening converge on a selective agonist for GPR30. Nat Chem Biol. (2006) 2:207-12. doi: 10.1038/nchembio775

20. Dennis MK, Burai R, Ramesh C, Petrie WK, Alcon SN, Nayak TK, et al. In vivo effects of a GPR30 antagonist. Nat Chem Biol. (2009) 5:421-7. doi: $10.1038 /$ nchembio. 168

21. Dennis MK, Field AS, Burai R, Ramesh C, Petrie WK, Bologa CG, et al. Identification of a GPER/GPR30 antagonist with improved estrogen receptor counterselectivity. J Steroid Biochem Mol Biol. (2011) 127:358-66. doi: 10.1016/j.jsbmb.2011.07.002

22. Lappano R, Rosano C, Santolla M.F, Pupo M, De Francesco E.M, De Marco $\mathrm{P}$, et al. Two novel GPER agonists induce gene expression changes and growth effects in cancer cells. Curr Cancer Drug Targets. (2012) 12:531-42. doi: $10.2174 / 156800912800673284$

23. Sinicropi MS, Lappano R, Caruso A, Santolla MF, Pisano A, Rosano $\mathrm{C}$, et al. (6-bromo-1,4-dimethyl-9H-carbazol-3-yl-methylene)-hydrazine (carbhydraz) acts as a GPER agonist in breast cancer cells. Curr Top Med Chem. (2015) 15:1035-42. doi: 10.2174/1568026615666150317221549

24. Maggiolini M, Santolla MF, Avino S, Aiello F, Rosano C, Garofalo A, et al. Identification of two benzopyrroloxazines acting as selective GPER antagonists in breast cancer cells and cancer-associated fibroblasts. Future Med Chem. (2015) 7:437-48. doi: 10.4155/fmc.15.3

25. Lappano R, Mallet C, Rizzuti B, Grande F, Galli GR, Byrne C, et al. The peptide $\mathrm{ER} \alpha 17 \mathrm{p}$ is a GPER inverse agonist that exerts antiproliferative effects in breast cancer cells. Cells. (2019) 8:590. doi: 10.3390/cells8060590

26. Zhang J, Zhang Y. GPCRRD: G protein-coupled receptor spatial restraint database for 3D structure modeling and function annotation. Bioinformatics. (2010) 26:3004-5. doi: 10.1093/bioinformatics/btq563

27. Prossnitz ER, Maggiolini M. Mechanisms of estrogen signaling and gene expression via GPR30. Mol Cell Endocrinol. (2009) 308:32-8. doi: 10.1016/j.mce.2009.03.026

28. Hamza A, Sarma MH, Sarma RH. Plausible interaction of an alpha-fetoprotein cyclopeptide with the G-protein-coupled receptor model GPR30: docking study by molecular dynamics simulated annealing. J Biomol Struct Dyn. (2003) 20:751-8. doi: 10.1080/07391102.2003.10506892

29. Lappano R, Santolla MF, Pupo M, Sinicropi MS, Caruso A, Rosano C, et al. MIBE acts as antagonist ligand of both estrogen receptor $\alpha$ and GPER in breast cancer cells. Breast Cancer Res. (2012) 14:R12. doi: 10.1186/bcr3096

30. Rosano C, Lappano R, Santolla MF, Ponassi M, Donadini A, Maggiolini M. Recent advances in the rationale design of GPER ligands. Curr Med Chem. (2012) 19:6199-206. doi: 10.2174/0929867311209066199

31. Rosano C, Ponassi M, Santolla MF, Pisano A, Felli L, Vivacqua A, et al. Macromolecular modelling and docking simulations for the discovery of selective GPER ligands. AAPS J. (2016) 18:41-6. doi: 10.1208/s12248-015-9844-3

32. Okada T, Sugihara M, Bondar AN, Elstner M, Entel P, Buss V. The retinal conformation and its environment in rhodopsin in light of a new $2.2 \AA$ crystal structure. J Mol Biol. (2004) 342:571-83. doi: 10.1016/j.jmb.2004.07.044

33. Cherezov V, Rosenbaum DM, Hanson MA, Rasmussen SG, Thian FS, Kobilka TS, et al. High-resolution crystal structure of an engineered human $\beta 2$-adrenergic G protein-coupled receptor. Science. (2007) 318:1258-65. doi: 10.1126/science.1150577

34. Rasmussen SG, DeVree BT, Zou Y, Kruse AC, Chung KY, Kobilka TS, et al. Crystal structure of the $\beta 2$ adrenergic receptor-Gs protein complex. Nature. (2011) 477:549-55. doi: 10.1038/nature10361

35. Arnatt CK, Zhang Y. G Protein-coupled estrogen receptor (GPER) agonist dual binding mode analyses toward understanding of its activation mechanism: a comparative homology modeling approach. Mol Inform. (2013) 32:647-58. doi: 10.1002/minf.201200136

36. Bruno A, Aiello F, Costantino G, Radi M. Homology modeling, validation and dynamics of the G protein-coupled estrogen receptor 1 (GPER-1). Mol Inform. (2016) 35:333-9. doi: 10.1002/minf.201501024

37. Wu B, Chien EY, Mol CD, Fenalti G, Liu W, Katritch V, et al. Structures of the CXCR4 chemokine GPCR with small-molecule and cyclic peptide antagonists. Science. (2010) 330:1066-71. doi: 10.1126/science.1194396
38. Méndez-Luna D, Martínez-Archundia M, Maroun RC, Ceballos-Reyes G, Fragoso-Vázquez MJ, González-Juárez DE, et al. Deciphering the GPER/GPR30-agonist and antagonists interactions using molecular modeling studies, molecular dynamics, and docking simulations. J Biomol Struct Dyn. (2015) 33:2161-72. doi: 10.1080/07391102.2014.994102

39. Méndez-Luna D, Bello M, Correa-Basurto J. Understanding the molecular basis of agonist/antagonist mechanism of GPER1/GPR30 through structural and energetic analyses. J Steroid Biochem Mol Biol. (2016) 158:104-16. doi: 10.1016/j.jsbmb.2016.01.001

40. Zhang J, Yang J, Jang R, Zhang Y. GPCR-I-TASSER: a hybrid approach to G protein-coupled receptor structure modeling and the application to the human genome. Structure. (2015) 23:1538-49. doi: 10.1016/j.str.2015.06.007

41. Roy A, Kucukural A, Zhang Y. I-TASSER: a unified platform for automated protein structure and function prediction. Nat Protoc. (2010) 5:725-38. doi: 10.1038/nprot.2010.5

42. Vidad AR, Macaspac S, Ng H-L. Locating ligand binding sites in G-protein coupled receptors using combined information from docking and sequence conservation. bioRxiv [Preprint]. (2019). doi: 10.1101/461681

43. Cirillo F, Lappano R, Bruno L, Rizzuti B, Grande F, Guzzi R, et al. AHR and GPER mediate the stimulatory effects induced by 3 -methylcholanthrene in breast cancer cells and cancer-associated fibroblasts (CAFs). J Exp Clin Cancer Res. (2019) 38:335. doi: 10.1186/s13046-019-1337-2

44. Thomas MP, Potter BV. The structural biology of oestrogen metabolism. J Steroid Biochem Mol Biol. (2013) 137:27-49. doi: 10.1016/j.jsbmb.2012.12.014

45. Chimento A, Casaburi I, Rosano C, Avena P, De Luca A, Campana C, et al. Oleuropein and hydroxytyrosol activate GPER/ GPR30-dependent pathways leading to apoptosis of ER-negative SKBR3 breast cancer cells. Mol Nutr Food Res. (2014) 58:478-89. doi: 10.1002/mnfr.201300323

46. Santolla MF, De Francesco EM, Lappano R, Rosano C, Abonante S, Maggiolini M. Niacin activates the G protein estrogen receptor (GPER)-mediated signalling. Cell Signal. (2014) 26:1466-75. doi: 10.1016/j.cellsig.2014.03.011

47. Papalia T, Lappano R, Barattucci A, Pisano A, Bruno G, Santolla MF, et al. Bodipy as a luminescent probe for detection of the $G$ protein estrogen receptor (GPER). Org Biomol Chem. (2015) 13:10437-41. doi: 10.1039/C5OB01827G

48. Moreno-Ulloa A, Mendez-Luna D, Beltran-Partida E, Castillo C, Guevara G, Ramirez-Sanchez I, et al. The effects of (-)-epicatechin on endothelial cells involve the G protein-coupled estrogen receptor (GPER). Pharmacol Res. (2015) 100:309-20. doi: 10.1016/j.phrs.2015.08.014

49. Kuiper GG, Lemmen JG, Carlsson B, Corton JC, Safe SH, van der Saag PT, et al. Interaction of estrogenic chemicals and phytoestrogens with estrogen receptor $\beta$. Endocrinology. (1998) 139:4252-63. doi: 10.1210/endo.139.10.6216

50. Grande F, Rizzuti B, Occhiuzzi MA, Ioele G, Casacchia T, Gelmini $\mathrm{F}$, et al. Identification by molecular docking of homoisoflavones from Leopoldia comosa as ligands of estrogen receptors. Molecules. (2018) 23:894. doi: 10.3390/molecules23040894

51. Puranik NV, Srivastava P, Bhatt G, John Mary DJS, Limaye AM, Sivaraman J. Determination and analysis of agonist and antagonist potential of naturally occurring flavonoids for estrogen receptor $(E R \alpha)$ by various parameters and molecular modelling approach. Sci Rep. (2019) 9:7450. doi: 10.1038/s41598-019-43768-5

52. Sarmiento V, Ramirez-Sanchez I, Moreno-Ulloa A, Romero-Perez D, Chavez D, Ortiz M, et al. Synthesis of novel (-)-epicatechin derivatives as potential endothelial GPER agonists: evaluation of biological effects. Bioorg Med Chem Lett. (2018) 28:658-63. doi: 10.1016/j.bmcl.2018.01.025

53. Bello M, Méndez-Luna D, Sarmiento V, Correa Basurto J, Najera N, Villarreal F, et al. Structural and energetic basis for novel epicatechin derivatives acting as GPER agonists through the MMGBSA method. J Steroid Biochem Mol Biol. (2019) 189:176-86. doi: 10.1016/j.jsbmb.2019.03.006

54. Martínez-Muñoz A, Prestegui-Martel B, Méndez-Luna D, Fragoso-Vázquez MJ, García-Sánchez JR, Bello M, et al. Selection of a GPER1 ligand via ligandbased virtual screening coupled to molecular dynamics simulations and its anti-proliferative effects on breast cancer cells. Anticancer Agents Med Chem. (2018) 18:1629-38. doi: 10.2174/1871520618666180510121431

55. Zacarías-Lara OJ, Méndez-Luna D, Martínez-Ruíz G, García-Sanchéz JR, Fragoso-Vázquez MJ, Bello $\mathrm{M}$, et al. Synthesis and in vitro evaluation of tetrahydroquinoline derivatives as antiproliferative compounds of breast cancer via targeting the GPER. Anticancer Agents Med Chem. (2019) 19:76071. doi: $10.2174 / 1871520618666181119094144$ 
56. Kezimana P, Dmitriev AA, Kudryavtseva AV, Romanova EV, Melnikova NV. Secoisolariciresinol diglucoside of flaxseed and its metabolites: Biosynthesis and potential for nutraceuticals. Front Genet. (2018) 9:641. doi: 10.3389/fgene.2018.00641

57. Ren GY, Chen CY, Chen WG, Huang Y, Qin LQ, Chen LH. The treatment effects of flaxseed-derived secoisolariciresinol diglycoside and its metabolite enterolactone on benign prostatic hyperplasia involve the $G$ proteincoupled estrogen receptor 1. Appl Physiol Nutr Metab. (2016) 41:1303-10. doi: 10.1139/apnm-2016-0332

58. Chen Y, Wang J, Hong DY, Chen L, Zhang YY, Xu YN, et al. Baicalein has protective effects on the $17 \beta$-estradiol-induced transformation of breast epithelial cells. Oncotarget. (2017) 8:10470-84. doi: 10.18632/oncotarget.14433

59. Cao LY, Ren XM, Li CH, Zhang J, Qin WP, Yang Y, et al. Bisphenol AF and bisphenol B exert higher estrogenic effects than bisphenol A via $G$ proteincoupled estrogen receptor pathway. Environ Sci Technol. (2017) 51:11423-30. doi: 10.1021/acs.est.7b03336

60. Leclercq G, de Cremoux P, This P, Jacquot Y. Lack of sufficient information on the specificity and selectivity of commercial phytoestrogens preparations for therapeutic purposes. Maturitas. (2011) 68:56-64. doi: 10.1016/j.maturitas.2010.10.003

61. Aiello F, Carullo G, Giordano F, Spina E, Nigro A, Garofalo A, et al. Identification of breast cancer inhibitors specific for $G$ protein-coupled estrogen receptor (GPER)-expressing cells. ChemMedChem. (2017) 12:127985. doi: $10.1002 / \mathrm{cmdc} .201700145$

62. Trichet M, Lappano R, Belnou M, Salazar Vazquez LS, Alves I, Ravault D, et al. Interaction of the anti-proliferative GPER inverse agonist ER $\alpha 17 \mathrm{p}$ with the breast cancer cell plasma membrane: from biophysics to biology. Cells. (2020) 9:447. doi: 10.3390/cells9020447

63. Pelekanou V, Kampa M, Gallo D, Notas G, Troullinaki M, Duvillier $\mathrm{H}$, et al. The estrogen receptor $\alpha$-derived peptide $\mathrm{ER} \alpha 17 \mathrm{p}\left(\mathrm{P}_{295}-\mathrm{T}_{311}\right)$ exerts pro-apoptotic actions in breast cancer cells in vitro and in vivo, independently from their ER $\alpha$ status. Mol Oncol. (2011) 5:36-47. doi: 10.1016/j.molonc.2010.11.001

Conflict of Interest: The authors declare that the research was conducted in the absence of any commercial or financial relationships that could be construed as a potential conflict of interest.

Copyright (c) 2020 Grande, Occhiuzzi, Lappano, Cirillo, Guzzi, Garofalo, Jacquot, Maggiolini and Rizzuti. This is an open-access article distributed under the terms of the Creative Commons Attribution License (CC BY). The use, distribution or reproduction in other forums is permitted, provided the original author(s) and the copyright owner(s) are credited and that the original publication in this journal is cited, in accordance with accepted academic practice. No use, distribution or reproduction is permitted which does not comply with these terms. 